\title{
Estimation of stochastic production functions: the state of the art*
}

Manyeki John Kibara

PhD Student

University of Szeged, Hungary

E-mail: manyeki.john@eco.uszeged.hu

\section{Balázs Kotosz}

(corresponding author)

Associate Professor

University of Szeged, Hungary

E-mail: balazskotosz@gmail.com
This article presents a comprehensive review of frontier studies for productivity analysis. The authors discuss the two main frontier approaches and highlight the reasons for selecting the parametric approach. The review also identifies the reason for considering unobserved heterogeneity when estimating firm performance. The classical stochastic frontier model is found to suffer from an empirical artefact in which the residuals of the production function may have positive skewness, contrary to the expected negative skewness which leads to estimated full efficiencies of all firms, as well as the possible problem of collinearity among inputs in the stochastic frontier model. By relaxing the hypotheses of random error symmetry and the independence of the components of the composite error, a sufficiently flexible re-specification of the stochastic frontier model can be achieved by decomposing the third moment of the composite error into three components that include the asymmetry of the inefficiency term, the asymmetry of the random error, and the dependence structure of the error components. Finally, instead of excluding insignificant variables from the model that can be of policy relevance, a principalcomponents-based solution can be adopted for collinearity in a stochastic frontier model.

\section{KEYWORDS:}

Efficiency analysis.

Heterogeneity.

Stochastic frontier.

DOI: $10.35618 / \mathrm{hsr} 2019.01 . e n 057$

* This research was supported by the project No. EFOP-3.6.2-16-2017-00007, titled 'Aspects on the development of intelligent, sustainable and inclusive society: social, technological, innovation networks in employment and digital economy'. The project has been supported by the European Union, co-financed by the European Social Fund and the budget of Hungary. 
Measuring production efficiency is an important issue in economics. A measure of a producer's performance is often useful for policy purposes, and the concept of efficiency provides a theoretical basis for such a measure. In productive efficiency measurements, we are familiar with three types of efficiency: technical, allocative, and economic efficiency. ${ }^{1}$ In this study, we consider TE (technical efficiency) because it is one of the important interventions proposed by modern economic theorists that could enhance producer productivity by ensuring TE of the factors of production that are at the producers' disposal (Farrell [1957]).

TE can be defined as a measure of the ability of a firm or DMU (decision-making unit) to produce the maximum output from a given level of inputs and technology (output-oriented) or achieve a certain output threshold using a minimum quantity of inputs under a given technology (input-oriented) (Farrell [1957], Galanopoulos et al. [2006]). As indicated by Färe-Lovell [1978], measurement of TE is an important tool for the following reasons. First, it is an indicator of performance success based on production units. Second, because it measures the causes of inefficiency, it becomes possible to explore the sources of efficiency differentials and eliminate the causes of inefficiency. Finally, identification of sources of inefficiency is essential to institute public and private policies designed to improve performance. Therefore, investigating factors that influence TE offers important insights on key variables that might be worthy of consideration in policymaking to ensure optimal resource utilization. TE can be modelled as either input-oriented/input-saving or outputoriented/output-augmenting (Coelli et al. [2005]). In this study, we adopt an outputoriented measure that indicates the magnitude of the output of the $i$-th firm relative to the output that could be produced by a fully efficient firm using the same input vector (Kumbhakar-Efthymios [2008]). The model is output oriented because firms are assumed to be output maximisers.

Since Farrell's [1957] seminal paper, TE has typically been analysed using two principal theoretical frameworks. These are the non-parametric but deterministic framework that are associated with DEA (data envelopment analysis) applied by Charnes-Cooper-Rhodes [1978], Barros-Wanke [2014], van Heerden-Rossouw [2014], and Kočišová [2015], and the parametric framework that is associated with the stochastic frontier approach simultaneously developed by Aigner-Lovell-Schmidt

\footnotetext{
${ }^{1}$ Technical efficiency reflects the effectiveness with which a given set of inputs are used to produce output, while allocative efficiency reflects how different resource inputs are combined to produce a mix of different outputs, given their respective prices. Economic efficiency comprises both and refers to producing the 'right' amount of allocative efficiency in the 'right' way of technical efficiency.
} 
[1977] and Meeusen-van der Broeck [1977]. Coelli et al. [2005] observed that the non-parametric framework has some limitations in that its deterministic frontiers attribute all deviations from the frontier to inefficiency and ignore any stochastic noise in the data. Similarly, since a standard non-parametric formulation creates a separate linear program for each DMU, the method is usually hampered by its computational intensity. In addition, since the method is non-parametric, statistical hypothesis tests, which are one of the main focuses of ongoing research, are difficult. However, the main advantage of this method lies in its axiomatic, non-parametric treatment of the frontier, which does not assume a particular functional form but relies on the general regularity properties such as free disposability, convexity, and assumptions concerning RTS (returns to scale; Kuosmanen-Kortelainen [2012]). In contrast, parametric approaches require an assumption about the functional form of the production function. However, the key advantage of a parametric method is its stochastic treatment of deviations from the frontier, which are decomposed into a non-negative inefficiency term and a random disturbance term that accounts for measurement errors and other random noise. This results in a measure that is more consistent with the potential production under 'normal' working conditions. To bridge the gap between parametric and non-parametric approaches, semi/nonparametric stochastic frontier models were developed, replacing the parametric frontier function with a non-parametric specification that can be estimated by kernel regression or local ML (maximum likelihood) techniques (Henderson-Simar [2005], Kumbhakar et al. [2007], Park-Simar-Zelenyuk [2008], Kuosmanen-Kortelainen [2012], Andor-Hesse [2014], Martins-Filho-Yao [2015], Vidoli-Ferrara [2015]).

While we agree that all these methods can be used to assess the level of producer performance, for reasons that become clear in the subsequent sections, their main shortcoming is that they assume firms are not heterogeneous but inefficient, since all inefficiency scores are estimated by assuming a homogeneous technology available to all producers. This suggests that the impact of inefficiency in productivity analysis is overestimated, and moreover, that the reasons for inefficiency might not be well identified. In this study, we review the developments in productivity analysis, specifically in situations where the homogeneity assumption is relaxed when producer performance is analysed.

The remainder of our paper proceeds as follows. In Section 1, we present a brief review of the theory of the stochastic frontier approach evolution. Section 2 presents the estimation procedure for the homogenous stochastic frontier model and concludes with how to estimate inefficiency and with the software that can analyse frontier models. Section 3 discusses the various approaches used when the composite error term presents the wrong skewness and the problem associated with multicollinearity in stochastic frontier modelling. The outlook for a heterogeneous stochastic frontier model is presented in Section 4, and Section 5 concludes. 


\section{Theoretical framework}

In this section, we overview the theory of production function in a point of view of producer's optimization with a focus on stochastic frontier analysis.

\subsection{On the production function}

A production function is a function that summarising the process of converting factors into a particular commodity. According to Coelli et al. [2005], a production function represents the maximum level of output attainable from alternative input combinations. Further, economic theory assumes that a production function is characterized by the following regularity properties or conditions (Chambers [1988]):

1. non-negativity: the value of output is a finite, non-negative real number;

2. weak essentiality: at least one input is required to produce positive output and no input implies no output;

3. monotonicity: an increase in inputs does not decrease output. Thus, all marginal products or elasticities are non-negative for a continuously differentiable production function; and

4. concavity in inputs: the law of diminishing marginal productivity applies in a continuously differentiable production function. Thus, to satisfy the second-order condition for optimization, all marginal products are non-increasing.

Assumption 1 defines the production function as a well-defined function of inputs while assumption 2 simply establishes that one cannot produce something from nothing. This is somewhat self-evident, at least for economists. Obviously, in other walks of life, such as in psychology, one can produce something without inputs (e.g. 'nice thoughts' can just be 'thought up' without inputs), but most examples of such things are outside the realm of economics. The monotonicity assumption (3) is also straightforward: increasing inputs leads to an increase in output (or, more precisely, no decrease in output). Assumption 4, the concavity in inputs of the production function, means that the more we add of a particular factor input, all other factors remaining constant - ceteris paribus - the less employing an additional unit of that factor input contributes to output as a whole. However, in practice these properties are not exhaustive and may not be universally maintained. For example, excess usage of inputs might result in input congestion, which relaxes the monotonicity assumption. Equally, according to Coelli et al. [2005], a stronger essentiality assumption often applies in cases where each and every input included proves to be essential in a production 
process. Moreover, flexibility of a production function (i.e. no restrictions imposed except theoretical consistency) is another desirable feature that allows data to capture information about critical parameters. Factual conformity with economic theory is also necessary (Sauer-Davidova-Gorton [2012]).

Nevertheless, the classical production function for a good $y$ can be specified in the following general form:

$$
Y_{i}=f\left(\mathbf{X}_{\mathbf{i j}} ; \boldsymbol{\beta}_{\mathbf{j}}\right)+\varepsilon,
$$

where $Y_{i}$ is the observed scalar output of producer $i, \mathbf{X}_{\mathbf{i j}}$ is a vector of $J$ inputs used by producer $i, f($.$) is the production function, for example, in the flexible first order$ Cobb-Douglas or flexible second translog specification, $\boldsymbol{\beta}_{\mathbf{j}}$ is a vector of technology parameters to be estimated, and $\varepsilon$ is the error term that is assumed to capture statistical noise in the model. For demonstration purposes, we adopt the representation of production technology for the one-output/two-input case imperfectly depicted in the diagrammatic form of 'hills' as presented by Pareto [1906] cited in Bruno [1987] in the figure. Output $Y$ is measured on the vertical axis. The two common inputs in many economics textbooks, which are marked as $\mathrm{L}$ and $\mathrm{K}$ and represent labour and capital, respectively, are depicted on the horizontal axes. The hill-shaped structure depicted in the figure is the production set. Notice that it includes all the area on the surface and in the interior of the hill.

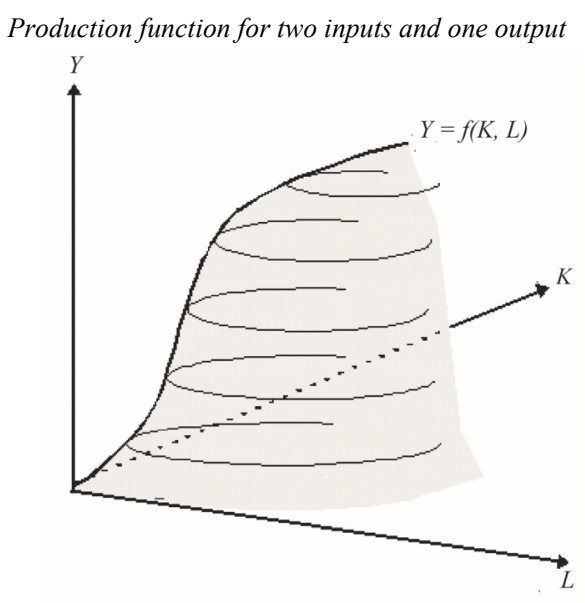

Source: Pareto [1906] cited in Bruno [1987].

A production decision is a feasible choice of inputs and output and is a particular point on or in the production hill. It will be 'on' the hill if it is technically efficient and 
'in' the hill if it is technically inefficient. Properly speaking, the production function $Y=f($.$) is only the surface (and not the interior) of the hill, and thus denotes the set$ of technologically efficient points of the production set. However, such technologically efficient points can only be obtained under a maintained hypothesis that in production and marketing behaviour, economic agents are driven by the objective of profit maximization and holding other factors (such as weather, economic adversaries, etc.) constant - ceteris paribus. However, in the literature, much of the empirical evidence suggests that although economic agents may indeed attempt to optimize from the theoretical point of view, they do not always succeed in maximizing their production function and fall short of the optimal level - the so-called satisficing behavioural concept proposed by Simon in 1957. Not all economic agents are always successful in solving their optimization problems, and again, very rarely do economic agents succeed in efficiently utilizing the inputs required to produce the outputs they choose to produce, given the technology at their disposal (Simon [1957], Greene [2012]). It is important, therefore, to specify a more comprehensive model conforming to current multivariate economic behaviour to be able to concisely and precisely develop appropriate product production and marketing strategies. This has generated the desire to recast the analysis of production away from the traditional classical production function approach toward a frontierbased approach. The subsequent section discusses the theoretical overview of production functions for estimating TE based on a frontier approach.

\subsection{Theory of frontier production function for TE estimation}

FPF (frontier production function) is an extension of the familiar regression model based on the theoretical premise that a production function; its dual, the cost function; or the convex conjugate of the two, the profit function, represents an ideal, the maximum output attainable given a set of inputs, the minimum cost of producing that output given the prices of the inputs, or the maximum profit attainable given the inputs, outputs, and prices of the inputs. Estimating frontier functions is the econometric exercise of making the empirical implementation consistent with the underlying theoretical proposition that no observed economic agent can exceed the ideal 'frontier', and deviations from this extreme represent individual inefficiencies. From the statistical point of view, this idea has been implemented by specifying a regression model recognizing the theoretical constraint that all observations lie within the theoretical extreme. Measurement of inefficiency is, then, the empirical estimation of the extent to which observed agents fail to achieve the theoretical ideal.

Since the seminal paper of Farrell [1957], TE has typically been analysed using two principal analytical frameworks. These two main frameworks include the nonparametric but deterministic approach, which includes DEA (Charnes-Cooper-Rhodes 
[1978]), FDH (free disposal hull; ${ }^{2}$ Deprins-Simar-Tulkens [1984]), and the parametric approach which includes SFA (stochastic frontier approach that was simultaneously proposed by Aigner-Lovell-Schmidt [1977] and Meeusen-van der Broeck [1977]), DFA (distribution-free approach ${ }^{3}$; Khoo-Fazari-Yang-Paradi [2013]), and TFA (thick frontier approach ${ }^{4}$, Berger-Humphrey [1992]). Among the aforementioned TE estimation approaches, the non-parametric DEA and parametric SFA are the two widely used methods for estimating efficiency, and, therefore, in this section we limit our discussion to these two. A detailed discussion on the distinction between parametric and nonparametric methods of frontier estimation can be found in Assaf-Josiassen [2016].

\subsubsection{Non-parametric DEA}

The DEA method is a non-parametric but deterministic approach for measuring efficiency. The method assumes that any deviations from optimal output levels are due to inefficiency rather than errors. The DEA model was proposed by Charnes-CooperRhodes [1978], who extended the relative efficiency concept of Farrell [1957] and simultaneously incorporated many inputs and outputs. This approach involves the use of linear programming methods to construct a non-parametric frontier using sample data, and then efficiency measures are computed relative to the surface (Coelli et al. [2005]). The envelopment form is generally preferred in the literature because it entails fewer constraints than the multiplier form. As Coelli et al. [2005] and KuosmanenKortelainen [2012] observed, the main advantage of the non-parametric DEA form lies in its axiomatic, non-parametric treatment of the frontier, which does not require explicit a priori determination of a production function form but relies on the general regularity properties such as free disposability, convexity, and assumptions concerning RTS. The approach measures the efficiency of each DMU relative to the highest observed performance of all other DMUs rather than against some average. Furthermore, another advantage is its ability to simultaneously accommodate multiple inputs and outputs in the estimation, thus providing a straightforward way of computing efficiency gaps between each DMU and efficient producers (Haji [2006]).

However, as Coelli et al. [2005] observed, the non-parametric DEA form has some limitations in that its deterministic frontiers attribute all deviations from the frontier to inefficiency and ignore any stochastic noise in the data. In contrast, although parametric SFA requires an assumption about the functional form of the production function, its key advantage is its stochastic treatment of deviations from the frontier, which are decomposed into a non-negative inefficiency term and a random

\footnotetext{
${ }^{2} \mathrm{FDH}$ requires minimal assumptions with respect to production technology; for example, it does not require convexity.

${ }^{3}$ DFA is a method capable of incorporating probability while still preserving the advantages of a functionfree and non-parametric modelling technique.

${ }^{4}$ TFA does not require distribution assumptions for random error and inefficiency terms but assumes that the inefficiencies differ between the highest and lowest quartile firms.
} 
disturbance term that accounts for measurement errors and other random noise so that the measure is more consistent with the potential production under 'normal' working conditions. It is within this context that we situate this study, and a parametric SFA form was preferred to allow simultaneously estimating stochastic production frontiers, TE, and key factors that affect TE. The development of a parametric stochastic FPF is discussed in detail in the subsequent section.

\subsubsection{Parametric stochastic FPF}

Since the publication of the seminal articles by Meeusen-van der Broeck [1977] and Aigner-Lovell-Schmidt [1977], the parametric SFA has become a popular tool for efficiency analysis. A stream of research has produced many reformulations and extensions of the original statistical models, generating a flourishing industry of empirical studies. A major survey that presents an extensive catalogue of these formulations is found in Kumbhakar-Know Lovell [2000] and more recently by Greene [2012]. Although SFA has been developed from isolated influences, the literature that directly influenced the development of parametric SFA has been the theoretical framework for production efficiency beginning in the 1950s (e.g. Debreu [1951]). Farrell [1957] was the first to empirically measure production efficiency and suggested that it can be analysed in terms of realized deviations from an idealized frontier isoquant. Kumbhakar-Ghosh-Mcguckin [1991] and Huang-Liu [1994] followed, and, using SFA as proposed by Aigner-Lovell-Schmidt [1977], designed a stochastic production model for the parametric estimation of both the stochastic frontier function and the inefficiency level. To date, the SFA has become the framework of choice of many scholars (e.g. Coelli [1995], Jondrow et al. [1982], KumbhakarTsionas-Sipiläinen [2009], Schmidt [2011], Mamardashvili-Bokusheva [2014], Baráth-Fertö [2015], Martinez et al. [2016], Bahta et al. [2018], Manyeki-Kotosz [2019]) in the estimation of TE levels for economic agents.

The SFA approach utilizes econometric techniques whose production models recognize technical inefficiency and the fact that random shocks beyond the control of producers may affect production. Unlike traditional classical production approaches that assume deterministic frontiers, SFA allows for deviations from the frontier, whose error can be decomposed to provide adequate distinction between technical inefficiency and random shocks. Using SFA ideas proposed by AignerLovell-Schmidt [1977], a stochastic FPF can be expressed using $J$ inputs $\left(X_{1}, X_{2}, \ldots, X_{J}\right)$ to produce output $Y$ as:

$$
Y_{i}=f\left(\mathbf{X}_{\mathbf{i j}} ; \boldsymbol{\beta}_{\mathbf{j}}\right) T E_{i}, I=1, \ldots, n, j=1, \ldots, J,
$$

where $Y_{i}$ is the observed scalar output of producer $i, \mathbf{X}_{\mathbf{i j}}$ is a vector of $J$ inputs used by producer $I, f\left(\mathbf{X}_{\mathbf{i j}} ; \boldsymbol{\beta}_{\mathbf{j}}\right)$ is the production frontier, $\boldsymbol{\beta}_{\mathbf{j}}$ is a vector of technology parame- 
ters to be estimated, and $T E_{i}$ denotes technical efficiency defined as the ratio of observed output to maximum feasible output. If $T E_{i}=1$, then the $i$-th firm obtains the maximum feasible output, while $T E_{i}<1$ provides a measure of the shortfall of the observed output from the maximum feasible output, in other words, technical inefficiency. Inefficiencies can be due to structural problems, market imperfections or other factors that cause economic agents to produce below their maximum attainable output.

A stochastic component is added to describe random shocks that affect the production process. These shocks are not directly attributable to the producer or the underlying technology and come from weather changes or economic adversity. We denote these effects with $\exp \left\{v_{i}\right\}$. Each producer faces a different shock, but we assume the shocks are random and are described by a common distribution. We can also assume that $T E_{i}$ is a stochastic variable, with a specific distribution function, common to all producers. We can write it as an exponential $T E_{i}=\exp \left\{-u_{i}\right\}$, where the firm-specific technical inefficiency, $u_{i} \geq 0$, since we required $T E_{i} \leq 1$. Thus, the stochastic FPF that assumes the presence of technical production inefficiency becomes:

$$
Y_{i}=f\left(\mathbf{X}_{\mathrm{ij}} ; \boldsymbol{\beta}_{\mathbf{j}}\right) \exp \left(\varepsilon_{i}\right), \varepsilon_{i}=v_{i}-u_{i}, i=1,2, \ldots, N,
$$

where $Y_{i}$ is the observed scalar output of producer $i, \mathbf{X}_{\mathbf{i j}}$ is a vector of $J$ inputs used by producer $i, X_{i} \sim \operatorname{IIDN}\left(\mu, \Sigma_{x}\right), f\left(\mathbf{X}_{\mathrm{ij}} ; \boldsymbol{\beta}_{\mathbf{j}}\right)$ is the deterministic production frontier, and $\boldsymbol{\beta}_{\mathbf{j}}$ is a vector of technology parameters to be estimated. $v_{i}$ is an IID (independent and identically distributed) random error associated with random shocks not under the control of economic agent $i$ or the underlying technology and comes from weather changes or economic adversity. This is the 'noise' component and is assumed to be a two-sided normally distributed variable with constant variance $\left(v \sim N\left(0, \sigma_{v}^{2}\right)\right) . T I_{i}=\exp \left(-u_{i}\right)$, where $u_{i} \geq 0$, since we required $T I_{i} \geq 0$, and is assumed to be independent of $v_{i}$ and follow a distribution which is either a halfnormal (Aigner-Lovell-Schmidt [1977]), exponential (Meeusen-van der Broeck [1977]), truncated-normal (Stevenson [1980]), or gamma distribution (Greene [2003] $)^{5}$ with variance $\sigma_{u}^{2}$. In any distribution, it follows that total variance is given

\footnotetext{
${ }^{5}$ In his paper, Greene [1990] applied all four distributions and the results showed that the gamma model generated a significantly different set of TE estimates from the other three distributions. This reflects the fact that estimates of TE can greatly depend on the distributions of the two error components and it is not clear a priori the basis for choosing an appropriate distributional assumption in a specific application. To solve this problem, one can allow for the greatest flexibility regarding the distribution shape and range of skewness for the distribution of the composed error $\varepsilon$, and/or compare AIC (Akaike's information criterion) among different distributions. Where AIC is an estimator of the relative quality of statistical models for a given set of data.
} 
by $\sigma^{2}=\sigma_{u}^{2}+\sigma_{v}^{2}$. This model is such that the possible production $Y_{i}$ is bounded above by the stochastic quantity, $f\left(X_{i}\right) \exp \left(v_{i}\right)$, hence the term stochastic frontier. When the data are in logarithmic form, $u_{i}$ is a measure of the percentage by which a particular firm fails to achieve the frontier or ideal production rate (Greene [2003]). Following Battese-Corra [1977], the departure of output from the frontier due to technical inefficiency is defined by a parameter $\eta$ given by: $^{6} \eta=\frac{\sigma_{u}^{2}}{\sigma^{2}}$, such that $0 \leq \eta \leq 1$. If the parameter $\eta=0$, then the variance of the technical inefficiency effect is zero and so the model reduces to the traditional mean response function, a specification with parameters that can be estimated using OLS (ordinary least squares). If $\eta$ is close to one, it indicates that the deviations from the frontier are due mostly to technical inefficiency and when $\eta=1$, a one-sided error component dominates the symmetric error component, and the model is a deterministic production function with no noise.

Since the SFA approach requires an assumption about the functional form of the production function, the next step corresponds to the selection of the functional form of the stochastic FPF. In the production function literature, the choice of functional form brings a series of implications with respect to the shape of the implied isoquants. In TE analysis literature, there are two distinct production function forms that are widely utilized: the first-degree flexible Cobb-Douglas and the seconddegree flexible transcendental logarithmic (hereafter abbreviated 'translog') production functions. The Cobb-Douglas production function has universally smooth and convex isoquants. The alternative translog model is not monotonic or globally convex, as is the Cobb-Douglas model, and imposing the appropriate curvature on it is generally a challenging problem. However, translog has its strength in that it is flexible and does not require a priori restrictions on the technologies to be estimated (Orea-Kumbhakar [2004], Alvarez-del Corral [2010]). To avoid the problem of model specification, this study adopts both functional formations (but subjects them to selection criteria) and assumes that the deterministic part $f\left(\mathbf{X}_{\mathbf{i}} ; \boldsymbol{\beta}\right)$ takes the loglinear form. Using SFA, we express the two functional forms as:

$$
\text { Cobb-Douglas: } \ln Y_{i}=\beta_{o}+\sum_{i=1}^{N} \boldsymbol{\beta}_{\mathbf{i}} \ln \mathbf{X}_{\mathbf{i}}+v_{i}-u_{i},
$$

translog: $\ln Y_{i}=\beta_{o}+\sum_{i=1}^{N} \boldsymbol{\beta}_{\mathbf{i}} \ln \mathbf{X}_{\mathbf{i}}+\frac{1}{2} \sum_{i=1}^{N} \sum_{k=1}^{N} \boldsymbol{\beta}_{\mathbf{i k}} \ln \mathbf{X}_{\mathbf{i k}} \ln \mathbf{X}_{\mathbf{i k}}+v_{i}-u_{i}$

${ }^{6}$ It is worth noting that other scholars use $\lambda$ given by $\sigma_{u} / \sigma_{v}$ in determining the contribution of technical inefficiency in stochastic production modelling. 
where $u_{i}=f\left(Z_{i}\right)=\delta_{0}+\sum_{i=1}^{M} \delta_{i} Z_{i}, i=1,2, \ldots, M \quad$ and $\quad Z_{i}$ are sociodemographic and other independent variables assumed to contribute to technical inefficiency. The term $\boldsymbol{\delta}$ is a vector of unknown parameters to be estimated.

\section{Model estimation procedure}

The procedure adopted in estimating the stochastic frontier production is ML, which is discussed in detail in a subsequent section. The ML estimation technique is adopted because the objective is to estimate the parameters of the statistical models by fitting them to the data. This makes sense because the error terms are assumed to follow a certain distribution which is non-normal, and our goal is to obtain the 'most likely' estimate rather than one that minimizes the sum of squares.

\subsection{ML: SFA for homogeneous technology}

In the case of cross-sectional data, the stochastic frontier model can only be estimated if the inefficiency effect components $u_{i}$ are stochastic and have particular distributional properties (Battese-Coelli [1995]). If we rewrite the stochastic frontier models (Equations $/ 4 /$ and $/ 5 /$ ) in matrix form as:

$$
\begin{gathered}
y_{i}=\alpha+\mathbf{X}_{\mathbf{i}}^{\prime} \boldsymbol{\beta}+\varepsilon_{i}, i=1, \ldots, N, \\
\varepsilon_{i}=v_{i}-u_{i}, v_{i} \sim N\left(0, \sigma_{v}^{2}\right), \text { and } u_{i} \sim \mathbf{F},
\end{gathered}
$$

where $y_{i}$ represents the logarithm of the output of the $i$-th productive unit, $\mathbf{X}_{\mathbf{i}}^{\prime}$ is a vector of inputs, and $\boldsymbol{\beta}$ is the vector of technology parameters. The composed error term $\varepsilon_{i}$ is the sum (or difference) of a normally distributed disturbance, $v_{i}$ represents measurement and specification error and a one-sided disturbance, $u_{i}$ denotes inefficiency. Moreover, $v_{i}$ and $u_{i}$ are assumed to be independent of each other and IID across observations. The distributional assumption, $\mathbf{F}$, required for identification of the inefficiency term, implies that this model can usually be estimated by ML, even though modified OLS or generalized method of moments estimators are possible (but often inefficient) alternatives (Belotti et al. [2013]). 


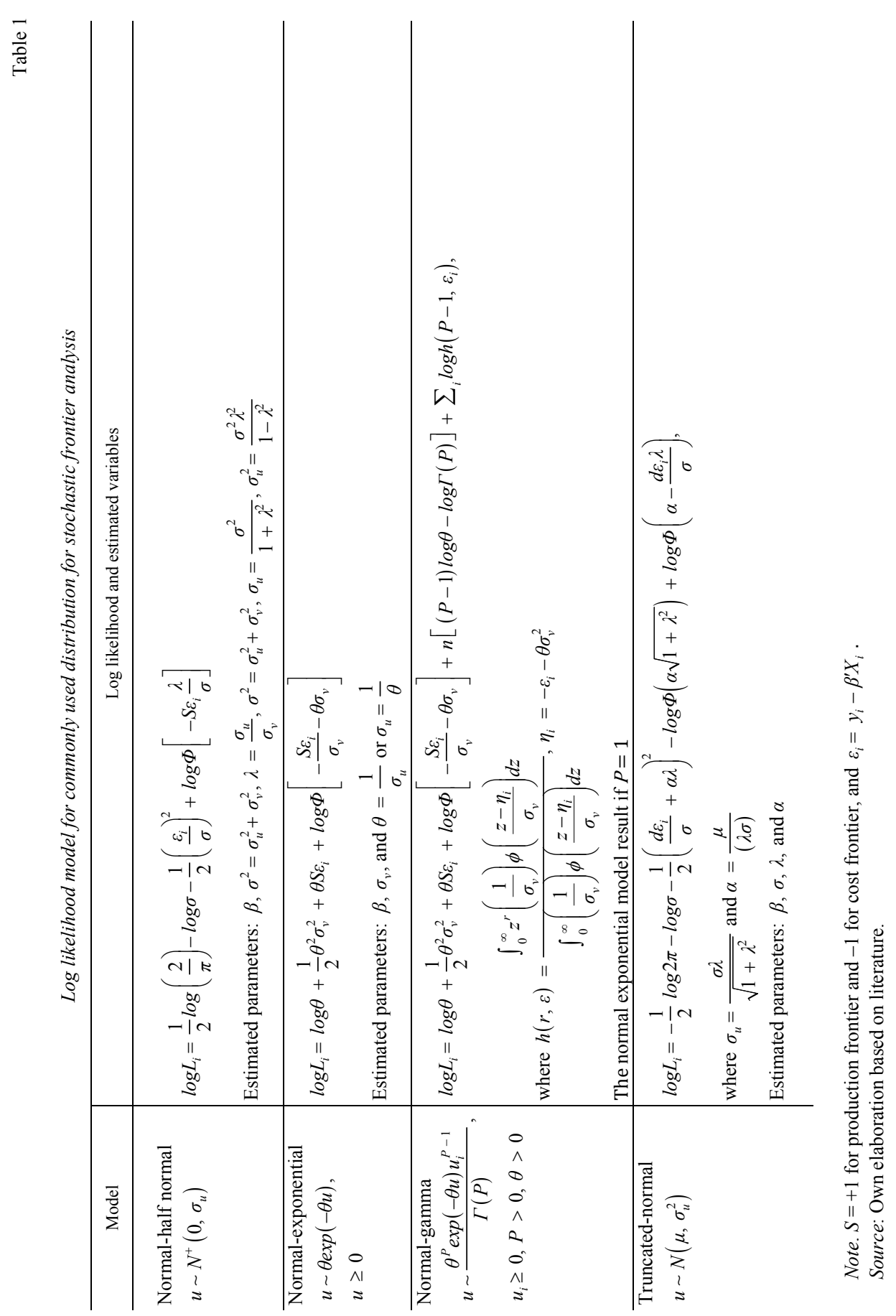


In incorporating inefficiency in SFA, Aigner-Lovell-Schmidt [1977] assumed a half-normal distribution, while Meeusen-van der Broeck [1977] opted for an exponential one. Other commonly adopted distributions are the truncated normal with a non-zero mean (Stevenson [1980]) and gamma distributions (Greene [2003]). The log likelihood models for these widely applied distributions in efficiency measurement literature are summarized in Table 1. In SFA, the widely canonical form of the Equation /6/ model is the normal-half normal model, $u \sim N^{+}\left(0, \sigma_{u}^{2}\right)$, $v \sim N\left[0, \sigma_{v}^{2}\right]$ which has commonly been used as the default form in most statistical software (STATA, EViews, LIMDEP, etc.). In this form, the major model estimates consist of $\boldsymbol{\beta}, \sigma=\sqrt{\sigma_{u}^{2}+\sigma_{v}^{2}}, \sigma$ and $\lambda=\frac{\sigma_{u}}{\sigma_{v}}$, and the usual set of diagnostic statistics for models fit by ML. The other basic form is the exponential model, $u \sim \theta \exp (-\theta u), u>0$, which has mean inefficiency $E(u)=\frac{1}{\theta}$, and standard deviation $\sigma_{u}=\frac{1}{\theta}$. The parameters estimated in the exponential specification are $\left(\boldsymbol{\beta}, \theta, \sigma_{u}, \sigma_{v}\right)$. Half-normal and exponential distributions have the common feature of having a mode at zero, which means most inefficiency is concentrated near zero. This may lead to significant underestimation of inefficiencies if the true inefficiency distribution has a non-zero mode.

The more flexible distributions with two or more parameters and a non-zero mean that are commonly adopted are the truncated normal $\left(u \sim N\left(\mu, \sigma_{u}^{2}\right)\right.$ ) (Stevenson [1980]) and gamma distributions $\left(u \sim \frac{\theta^{P} \exp (-\theta u) u_{i}^{P-1}}{\Gamma(P)}\right)$, where $u_{i} \geq 0, P>0, \theta>0$ (Greene [2003]). For the normal-gamma model, the twoparameter distributional form allows both the shape and location to vary independently. The log likelihood for this model is equal to the log likelihood for the normal-exponential model plus a term that is produced by the difference between the exponential and gamma distributions and the normal exponential model result if $P=1$. The normal-truncated normal model relaxes the implicit restriction in the normal-half normal model that the mean of the underlying inefficiency variable is zero. There are only two formulations of the normal-truncated normal model in the literature. The common one, which is applied in this study, is the extended model by Stevenson [1980] in which $\mu$, the mean of $u$, is assumed to be nonzero; $u \sim N\left(\mu, \sigma_{u}^{2}\right)$ and $v \sim N\left[0, \sigma_{v}^{2}\right]$, and the $\log$ likelihood function is then maxim- 
ized with respect to $\boldsymbol{\beta}, \sigma, \lambda$, and $\alpha$. The other is Battese-Coelli's [1995] formulation, $u=\mu+w$, where $w$ is a truncated normal, such that $w>-\mu$. The distributions shown in Table 1 are those most often applied.

Regarding panel data modelling, the availability of a richer set of information in a panel dataset allows one to relax some of the assumptions previously imposed and to consider a more realistic characterization of the inefficiencies. Model /6/ was extended by Pitt-Lee [1981] to longitudinal data, and they proposed the ML estimation of the following normal-half normal stochastic frontier model:

$$
\begin{aligned}
& y_{i t}=\alpha+\mathbf{X}_{\mathbf{i t}}^{\prime} \boldsymbol{\beta}+\boldsymbol{\varepsilon}_{\mathbf{i t}}, i=1, \ldots, N, t=1, \ldots, T_{i}, \\
& \boldsymbol{\varepsilon}_{\mathbf{i t}}=\mathbf{v}_{\mathbf{i t}}-u_{i}, \mathbf{v}_{\mathbf{i t}} \sim N\left(0, \sigma_{v}^{2}\right), \text { and } u_{i} \sim N^{+}\left(0, \sigma_{v}^{2}\right) .
\end{aligned}
$$

Battese-Coelli [1988] extended model /7/ for the normal-truncated normal case and defined a density function for $u_{i}$ by

$$
f_{u_{i}}(u)=\frac{\exp \left[\frac{-\frac{1}{2}(u-\mu)^{2}}{\sigma^{2}}\right]}{(2 \pi)^{\frac{1}{2}} \sigma\left[1-\Phi\left(\frac{u}{\sigma}\right)\right]}, u>0,
$$

where $\Phi($.$) denotes the distribution function of standard normal random variables.$

The estimation of a stochastic frontier panel model with time-invariant inefficiency can also be performed following Cornwell-Schmidt-Sickles's [1990] model, which relaxed the conventional fixed-effects estimation techniques (the panel model of Schmidt-Sickles [1984], where inefficiency is allowed to be correlated with the frontier regressors to avoid distributional assumptions of $u_{i}$ by specifying a stochastic frontier model with individual-specific slope parameters expressed as:

$$
\begin{gathered}
\mathbf{y}_{\mathrm{it}}=\alpha+\mathbf{X}_{\mathrm{it}}^{\prime} \boldsymbol{\beta}+\boldsymbol{\varepsilon}_{\mathrm{it}}, i=1, \ldots, N, t=1, \ldots, T_{i}, \\
\mathbf{u}_{\mathrm{it}}=\boldsymbol{\omega}_{\mathbf{i}}+\boldsymbol{\omega}_{\mathbf{i} 1} t+\boldsymbol{\omega}_{\mathbf{i} 2} t^{2} .
\end{gathered}
$$

In this model, the parameters are estimated by extending the conventional fixedand random-effects panel-data estimators. This quadratic specification allows for a 
unit-specific temporal pattern of inefficiency. Lee-Schmidt [1993] employed a slightly different estimation procedure for $\mathbf{u}_{\mathbf{i t}}$, which can be specified as:

$$
\mathbf{u}_{\mathbf{i t}}=g(t) \times u_{i},
$$

where $g(t)$ is represented by a set of time dummy variables. This specification is more parsimonious than /9/ and does not impose any parametric form, but it is less flexible because it restricts the temporal pattern of $\mathbf{u}_{\mathbf{i t}}$ to be the same for all productive units. ML for a time-varying stochastic frontier model in which $g(t)$ can be specified follows the two formulations:

$$
\begin{aligned}
& \text { Kumbhakar [1990]: } g(t)=\left\{1-\exp \left(\gamma t+\delta t^{2}\right)\right\}^{-1}, \\
& \text { Battese-Coelli [1992]: } g(t)=\exp \left\{-\left(t-T_{i}\right)\right\}^{-1} .
\end{aligned}
$$

Moreover, the time-varying issue can be approached through a normal-half normal model with unit-specific intercepts obtained by replacing Equation /7/ by Greene's [2005] specification expressed as:

$$
\mathbf{y}_{\mathrm{it}}=\alpha+\mathbf{X}_{\mathrm{it}}^{\prime} \boldsymbol{\beta}+\boldsymbol{\varepsilon}_{\mathrm{it}}, \boldsymbol{\varepsilon}_{\mathrm{it}}=\mathbf{v}_{\mathrm{it}}-\mathbf{u}_{\mathrm{it}} .
$$

Compared with models $/ 11 /$ and $/ 12 /$, this specification allows one to disentangle time-varying inefficiency from unit-specific time-invariant unobserved heterogeneity.

\subsection{Estimating individual inefficiency}

The ultimate goal of fitting the frontier models is to estimate the technical inefficiency term $u_{i}$ in the stochastic model using the sample observations. Unfortunately, it is not possible to estimate $u_{i}$ directly from any observed sample information. In standard SFA, where the frontier function is the same for every firm, we estimate inefficiency relative to the frontier for all observations. The Jondrow et al. [1982] estimator of the conditional distribution of $u$ given $\varepsilon, \hat{E}(u \mid v-u)$, where $\varepsilon=v_{i}-u_{i}$ is the standard estimator. Thus, a point estimate of the inefficiencies can be obtained using the mean $\hat{E}(u \mid \varepsilon)$ of this conditional distribution expressed as:

$$
\hat{E}(u \mid \varepsilon)=\frac{\sigma \lambda}{1+\lambda^{2}}\left[\frac{\Phi(\varepsilon \lambda / \sigma)}{1-\Phi(\varepsilon \lambda / \sigma)}\right]-\frac{\varepsilon \lambda}{\sigma} .
$$


This is an indirect estimator of $u$. Once point estimates of $u$ are obtained, estimates of TE can then be derived as $E f f=\exp (-\hat{u})$, where $\hat{u}$ is $\hat{E}(u \mid \varepsilon)$.

In the present case of a latent class stochastic frontier model, we estimate as many frontiers as there are number of classes. What remains an issue here is how to measure the efficiency level of an individual firm when there is no unique technology against which inefficiency is to be computed. In a traditional stochastic frontier model, the output-oriented TE can be calculated as a ratio of the observed output to the corresponding frontier output, given the available technology, using the following expression (the dependent variable expressed in log):

$$
T E_{i}=\frac{Y_{i}}{Y_{i}^{*}}=\frac{f\left(X_{i} ; \beta_{i}\right) \exp \left(v_{i}-u_{i}\right)}{f\left(X_{i} ; \beta_{i}\right) \exp \left(v_{i}\right)}=\exp \left(-u_{i}\right) .
$$

Here $Y_{i}$ is the observed output and $Y_{i}^{*}$ is the frontier output. Once estimates of $\mathrm{TE}$ are obtained, the indirect estimator of inefficiency can be obtained using $T I=1-\exp \left(-T E_{i}\right)$. This is the inefficiency parameter that enters into the inefficiency effects model as the dependent variable.

\subsection{Estimating RTS}

In a production model, the estimation of RTS brings a series of implications with respect to the shape of the implied isoquants. In particular, the Cobb-Douglas production function has universally smooth and convex isoquants. The alternative translog model is not monotonic or globally convex, as is the Cobb-Douglas model, and imposing the appropriate curvature on them is generally a challenging problem. Therefore, we restrict our estimation of RTS to the log-linear Cobb-Douglas functional form of a stochastic frontier. Since output and input variables in the production function estimated are normalized by their means prior to estimation and are all expressed in natural logarithms, it is possible to calculate output elasticities by partially differentiating the Cobb-Douglas latent class stochastic frontier function (Equation /2/) by each of the inputs as follows:

$$
\text { classical stochastic frontier: } \frac{\partial Y_{i}}{\partial X_{i}}=E_{i}=\beta_{i} \text { and } R T S_{i}=\sum_{j=1}^{J} E_{i},
$$

where RTS represents returns to scale. The elasticities are computed for each variable input with respect to output production, while the sum of all input elasticities gives a measure of RTS. 


\subsection{SFA software}

To estimate the parameters for the models and simulate their economic implications, four software packages are commonly used. These are the commercial package known as LIMDEP Version 11 Econometric Software (Greene [2016]), a free-ware package known as FRONTIER 4.1 (Coelli [1996]), also nested in STATA Version 15 (StataCorp [2011]), and free-ware in R project often developed on parallel - a 'frontier' and an 'sfa' package nested in R project (Straub-Straub [2016], Behr [2015], Coelli-Henningsen-Henningsen [2017]). In all packages, OLS estimates are obtained first to serve as starting values after adjusting the intercept and variance terms using the modified OLS estimator. However, it is worth noting that these packages are rather different in their treatment of cases where composite residuals have the 'wrong' skewness, since in the case of LIMDEP, when the OLS residuals have positive skewness, the program stops with a message stating, 'Stoch. Frontier: OLS residuals have wrong skew', while with FRONTIER, STATA and R software, estimation proceeds even if the OLS residuals have positive skewness. In such a case, OLS is an MLE (maximum likelihood estimate). However, the OLS standard error estimates that are reported should not be taken as estimates of the standard error of the MLE estimates. The OLS standard error estimates are conditioned on $\gamma=0$ and consequently understate the true standard errors, ignoring the uncertainty about $\gamma$, and thus, the conventional standard error estimates of the MLE estimates are unavailable due to singularity of the negative Hessian of the log-likelihood in this case.

Note, in FRONTIER, STATA, and R, estimation will proceed because after the OLS estimates have been obtained, a grid search procedure is used to find a starting value for $\gamma$; then these starting values are used in the DFP (Davidon-FletcherPowell) algorithm (Fletcher-Powell [1963], Davidon [1991]). If the OLS residuals have positive skewness, FRONTIER/STATA/R return a very small estimate for $\gamma$, but typically not zero. In addition, FRONTIER, STATA and/or R do not use the inverse negative Hessian to estimate the variance-covariance matrix, but rather the DFP direction matrix, which is an approximation of the inverse negative Hessian. The accuracy of approximating the Hessian using the DFP direction matrix suffers if the algorithm iterates only a few times or if the objective function is far from quadratic. Table 2 summarizes the frontier models that can be estimated by the four software packages. With regard to cross-sectional functions, all software can estimate at least two types of model distributions, with the exception of LIMPED, which can analyse all distributions. With regard to frontier models for panel data, the distinct advantage of LIMPED 11 and FRONTIER 4.1 is that, in addition to Battese-Coelli's [1988] model where the inefficiency component is firm-specific but time-invariant, they can estimate variants of the basic models where the inefficiency component is time-variant (Battese-Coelli [1992]) and where the inefficiency term is a function of 
a vector of firm-specific variables (Battese-Coelli [1995]) for half-normal and truncated normal distribution model conformation. However, all four software packages can estimate firm-specific time-variant and invariant frontier models for both balanced and unbalanced panel data for half-normal distributions.

Table 2

Summary of the frontier models that can be estimated by the four common software

\begin{tabular}{l|c|c|c|c}
\hline \multicolumn{1}{c|}{ Model } & LIMDEP 11 & FRONTIER 4.1 & STATA 15 & \multirow{2}{*}{ R projects } \\
\hline \multicolumn{5}{|c|}{ Cross-sectional function } \\
Half-normal distribution & Yes & Yes & Yes & Yes* \\
\hline Exponential distribution & Yes & No & Yes & Yes* \\
\hline Normal-gamma distribution & Yes & No & No & No \\
\hline Truncated normal distribution & Yes & Yes & Yes & Yes* \\
\hline
\end{tabular}

Panel data function

Time-invariant firm-specific inefficiency

\begin{tabular}{l|c|c|c|c} 
Half-normal distribution & Yes & Yes & Yes & Yes** \\
\hline Truncated normal distribution & Yes & Yes & No & No \\
\hline
\end{tabular}

\begin{tabular}{l|c|c|c|c} 
Truncated normal distribution & Yes & Yes & No & No \\
\hline \multicolumn{3}{r}{ Time-variant firm-specific inefficiency } & Yes & Yes** \\
Half-normal distribution & Yes & Yes & No & No \\
\hline Truncated normal distribution & Yes & Yes & No & No \\
\hline Effect-specific panel data function & Yes & Yes & & \\
\hline
\end{tabular}

* Frontier model estimable with 'frontier' package.

** Frontier model estimable with 'sfa'package.

Source: Own elaboration based on software specifications.

\section{Skewness and multicollinearity}

Since the error term in the classical stochastic frontier model is a convolution of two terms (a one-sided inefficiency term plus a classical symmetric statistical noise term), the major challenge analysts often face is related to the choice of the distributions of the random variables (the four common distributions are displayed in Table 1). All of these one-sided distributions are expected to have positive skewness, which can be shown using Greene's [1990] third moment of $\varepsilon_{i}$ given by:

$$
E\left\{\left[\varepsilon_{i}-E\left(\varepsilon_{i}\right)\right]^{3}\right\}=-E\left\{\left[u_{i}-E\left(u_{i}\right)\right]^{3}\right\} .
$$


The positive skewness for $u_{i}$ implies a negative skewness for $\varepsilon_{i}$. From $/ 17 /$, it is clear that $\hat{\mu}_{3, n}=n^{-1} \sum_{i=1}^{n} \hat{\varepsilon}_{i, O L S}^{3}$ is a consistent estimator of the negative of the third moment of $u_{i}$, which gives the sign of the skewness of $u_{i}$. However, as illustrated by Simar-Wilson [2010] using Monte Carlo experiments, in a finite sample the sign of $\hat{\mu}_{3, n}$ is very often positive, even though the negative is expected. In this literature, researchers say that they observe the 'wrong' skewness when the sign of the empirical skewness is positive. The consequence of a 'wrong' skewness, as shown, for example, by Waldman [1982], is that the modified OLS and MLE estimates of the slope are identical to the OLS slope, and there are no inefficiencies, implying the mean and variance of $u_{i}$ are estimated at zero. Therefore, all firms are supposed to be efficient - operating at the optimal frontier. In stochastic frontier literature, the wrong skewness phenomenon was initially pointed out by Green-Mayes [1991].

To overcome this problem, several strategies have been proposed for the distribution functions of $u_{i}$ with negative asymmetry. By way of example, these include the use of the binomial probability function (Carree [2002]), Weibull distribution (Tsionas [2007]), double truncated normal distribution (Qian-Sickles [2009], Almanidis-Sickles [2011], Almanidis-Qian-Sickles [2014]), finite sample adjustment to the existing estimators (Feng-Horrace-Wu [2015]), and generalizing the distribution used for the inefficiency variable (Hafner-Manner-Simar [2018]). All these strategies assume that the inefficiency term is bounded above and below. The common feature of all these strategies is that the phenomenon of wrong skewness was approached from an inefficiency error term point of view. According to BonannoDe Giovanni-Domma [2017], this only partially addresses the problem because the wrong skewness anomaly is a direct consequence of all the assumptions underlying the stochastic frontier model specification. Therefore, Bonanno-De GiovanniDomma [2017] describe a more general framework, where they relaxed the hypothesis of symmetry for $v_{i}$, of positive skewness for $u_{i}$, and of independence between $u_{i}$ and $v_{i}$, and extended Greene's [1990] third central moment of the composite error as:

$$
\begin{aligned}
E\left\{\left[\varepsilon_{i}-E\left(\varepsilon_{i}\right)\right]^{3}\right\}= & -E\left\{\left[u_{i}-E\left(u_{i}\right)\right]^{3}\right\}+E\left\{\left[v_{i}-E\left(v_{i}\right)\right]^{3}\right\}+3 \operatorname{cov}\left(u_{i}^{2}, v_{i}\right)- \\
& -3 \operatorname{cov}\left(u_{i}, v_{i}^{2}\right)-6\left[E\left(u_{i}\right)-E\left(v_{i}\right)\right] \operatorname{cov}\left(u_{i}, v_{i}\right) .
\end{aligned}
$$

From Equation $/ 18 /$, the sign of the asymmetry of $u_{i}, v_{i}$, and the dependence between $u_{i}$ and $v_{i}$ affect the expected sign of the asymmetry of the composite error. In Bonanno-De Giovanni-Domma's [2017] model, the dependence structure is modelled with a copula function that allows them to specify the joint distribution with 
different marginal probability density functions. The copula joint distribution function, $f_{U, V}\left(u_{i}, v_{i}\right)$ has the following standard representation:

$$
f_{U, V}\left(u_{i}, v_{i}\right)=f_{U}\left(u_{i}\right) g_{v}\left(v_{i}\right) c_{\theta}\left[F_{U}\left(u_{i}\right) G_{V}\left(v_{i}\right)\right],
$$

where $f_{U}($.$) and g_{v}($.$) are their probability density functions, and F_{U}($.$) and$ $G_{V}($.$) are their distribution functions. c_{\theta}\left[F_{U}\left(u_{i}\right) G_{V}\left(v_{i}\right)\right]=\frac{\partial^{2} c_{\theta}\left[F_{U}\left(u_{i}\right) G_{V}\left(v_{i}\right)\right]}{\partial F_{U}\left(u_{i}\right) \partial G_{V}\left(v_{i}\right)}$ is the density copula and the probability density function of the composite error is the convolution of the joint density expressed as:

$$
f_{\varepsilon_{i}}\left(\varepsilon_{i}\right)=\int_{0}^{+\infty} f_{U, V}\left(u_{i}, \varepsilon_{i}+u_{i}\right) .
$$

Now $\varepsilon_{i}=\bar{y}_{i}-\bar{x}_{i} \beta$, then the likelihood function becomes:

$$
L=\prod_{i=1}^{N} f_{\varepsilon_{i}}\left(\bar{y}_{i}-\bar{x}_{i} \beta ; \Theta\right)
$$

and the technical efficiency $\left(T E_{\Theta}\right)$ is:

$$
T E_{\Theta}=E\left[e^{u} \mid \varepsilon=\varepsilon^{*}\right]=\frac{1}{f_{\varepsilon}\left(\varepsilon^{*}, \Theta\right)} \int_{0}^{+\infty} \int f_{U, V}(u, \varepsilon+u) d u
$$

where $\bar{x}_{i}$ is the $i$-th row of $\bar{x}$. Applying the copulas technique, Bonanno-De Giovanni-Domma's [2017] present a new specification for the composite error, which gives rise to a semi-closed expression for the composite error of a stochastic production frontier through an exponential random variable $\left(1-e^{-\frac{u}{\delta_{u}}}, \delta_{u}>0\right)$, using a slight modification of the Type I GL (generalized logistic) distribution. They specify the random component of the composite error as:

$$
G L=G_{v}(v)=\left\{1+e^{-\frac{v-\delta_{v}\left[\Psi\left(\alpha_{v}\right)+\Psi(1)\right]}{\delta_{v}}}\right\}^{-\alpha_{v}}, \alpha_{v}, \delta_{v}>0 .
$$


The final ingredient in their specification is the FGM (Farlie-GumbelMorgenstern) copula expressed as:

$$
F G M=F_{u} G_{v}\left[1+\theta\left(1-F_{u}\right)\left(1-G_{v}\right)\right], \theta \in(-1.1) .
$$

The other drawback in estimating the stochastic frontier model /6/ is associated with collinearity among inputs, which leads to the multicollinearity problem, and subsequent loss of estimate precision. When collinearity arises, separating the individual effects of each independent variable could be a difficult task and the precision loss is manifested in large estimated variances of estimates; moreover, estimated coefficients can have incorrect signs and impossible magnitudes. In the literature, the most common strategy for solving the multicollinearity problem has been to exclude the input whose correlation with other inputs is quite high or to eliminate an apparently insignificant variable, which can produce large changes in estimates (e.g. Gro $\beta$ [2003], Filippini-Hrovatin-Zoric [2008]). Other studies sacrifice the advantage of flexibility in the functional form for the deterministic component due to the cost of statistically insignificant estimates generated by unreliable parameter estimates resulting from linear dependencies between inputs (Kumbhakar-Knox Lovell [2000], Filippini-HrovatinZorić [2008]). The most recent strategy was proposed by Castano-Gallon [2017], who adopted a principal-components-based solution for multicollinearity in a stochastic frontier model. In Castano-Gallon's [2017] model, the stochastic frontier model /6/ is re-parameterized in terms of all $k$ principal components and the corresponding coefficient vector is restricted to those principal components associated with the $r<k$ nonzero eigenvalues. By the orthogonality of $P$ (i.e. $P P^{T}=P^{T} P=I$, model $/ 6 /$ can be re-parameterized as:

$$
y=\alpha_{0} 1+X^{\prime} P P^{T} \beta+v-u=\alpha_{0} 1+Z \theta+v-u,
$$

where $Z=X P=\left(z_{1}, z_{2}, \ldots, z_{k}\right)$ is the matrix of principal components $x_{j}=X p_{j}$ with the property $z_{j}^{T} z_{j}=\lambda_{j}, \forall j$, and $\theta=P^{T} \beta$. To implement their strategy, they restrict $\beta$ to the subspace spanned by the columns $\lambda_{1} p_{1}, \lambda_{2} p_{2}, \ldots, \lambda_{r} p_{r}$, where $\lambda_{1} \geq \lambda_{2} \geq \ldots \geq \lambda_{r}>0 \quad$ are the $r<k$ largest eigenvalues of $X^{T} X$ and $\lambda_{r+1} \approx \lambda_{r+2} \approx \ldots \geq \lambda_{k} \approx 0$.

\section{Outlook: heterogeneous production technologies}

As Alvarez-del Corral-Tauer [2012] and Sauer-Morrison Paul [2013] observed, a common limitation while using the above parametric SPF (stochastic production 
function) model is that the model assumes homogeneous production technologies and no attention is paid to the possible presence of heterogeneity, particularly in the production decision process.

\subsection{Model specification}

Many case studies (e.g. Alvarez-del Corral [2010], Sauer-Davidova-Gorton [2012], Kellermann [2014], Otieno Hubbard-Ruto [2014], Baráth-Fertö [2013], Martinez et al. [2016], Bahta et al. [2018]) have shown resource and production environments surrounding production societies are highly heterogeneous. The use of a single characteristic to cluster a sample might be challenging when heterogeneity is likely to arise from more than one factor, leading to incomplete division of the sample. In this regard, we need to consider the possibility of production heterogeneity. To account for technology heterogeneity, several approaches on how to relax the restrictive assumption that all firms share the same technological production have been proposed in the efficiency literature. First, stochastic metafrontier approach proposed by Battese-Rao [2002] follows a two-stage process that involves first splitting the sample into groups based on some a priori information about firms (e.g. firm ownership, production system, firm location, etc.), and second stage estimation of separated frontier functions for each group (e.g. Battese-Rao-O'Donnell [2004], Newman-Matthews [2006], Balcombe-Rahman-Smith [2007], Moreira-Bravo-Ureta [2010], OtienoHubbard-Ruto [2014], Melo-Becerra-Orozco-Gallo [2017]). ${ }^{7}$ However, the use of a priori information might be challenging in cases where heterogeneity is likely to arise from more than one factor, leading to incomplete division of the sample (Alvarezdel Corral-Tauer [2012], Sauer-Morrison Paul [2013]). Second, some authors allow for consideration of multiple exogenous characteristics when splitting the sample into groups by using statistical techniques such as cluster analysis (e.g. Maudos-PastorPérez [2002], Alvarez et al. [2008]). The salient characteristic of the two aforementioned approaches is the use of a two-stage approach (i.e. in the first step, the sample is divided into groups, and then separate regressions are performed for each of them), which has the shortcoming that the information contained in a given sub-sample cannot be used to estimate the technology of firms that belong to other sub-samples. According to Alvarez-del Corral [2010], this limitation is important because firms included in separate groups often share some common features.

To overcome this limitation, one option is to use Greene's [2005] approach of implementing a random coefficients model, which accounts for firm technology

${ }^{7}$ For example, Otieno-Hubbard-Ruto [2014] split the sample into three sub-samples (pastoral, agropastoral, and ranches) based on a single exogenous characteristic and estimated different production frontiers for each group, without considering within-group characteristics that may be unobservable. 
differences in the form of a continuous parameter variation. Another possibility is to use cluster algorithms as proposed by Alvarez et al. [2008] or apply the econometric techniques proposed by Kumbhakar-Tsionas-Sipiläinen [2009], where a system approach is used to simultaneously estimate the production technologies and the choice equation, or by LCMs (latent class model) as applied by Alvarez-del Corral [2010] and Sauer-Morrison Paul [2013]. Although heterogeneity can be modelled using several methodological approaches, in this study we adopted an LCM in an SFA framework because it has been increasingly recognized as a suitable way to deal with technology heterogeneity. Additionally, comparative analysis conducted by Alvarezdel Corral-Tauer [2012] between a two-stage SFA approach versus an LCSFA revealed that the LCSFA provided a more satisfactory separation of technologies in the sample. However, despite LCSFA proving superior, there are still very few empirical applications of the latent class in the SFA framework.

Since the introduction of LCSFA, a stream of research has produced many reformulations and extensions of the model into various sectors, generating a flourish of empirical studies. By way of example, the LCSFA was applied in agricultural-related contexts (Alvarez-Arias [2013], Sauer-Morrison Paul [2013], Bahta et al. [2018]), finance (e.g. Brummer-Loy [2000], Poghosyan-Kumbhakar [2010]), transport (e.g. Cullmann-Farsi-Filippini [2012]) and health services (e.g. Widmer [2015]). All these papers found evidence that if technology heterogeneity is not considered when estimating TE, the results could be misleading and therefore any policy recommendation arising from them would not be accurate. In this study, we adopt the LCM in the SFA framework as was formulated in Alvarez-Arias [2013], and rewrite Equations $/ 4 /$ and $/ 5 /$ as follows:

$$
\text { Cobb-Douglas: } \ln Y_{i}=\beta_{o}\left|j+\sum_{i=1}^{N} \beta_{i}\right| j \ln X_{i}+v_{i}\left|j-u_{i}\right| j
$$

translog: $\ln Y_{i}=\beta_{o}\left|j+\sum_{i=1}^{N} \beta_{i}\right| j \ln X_{i}+\frac{1}{2} \sum_{i=1}^{N} \sum_{k=1}^{N} \beta_{i k}\left|j \ln X_{i k} \ln X_{i k}+v_{i}\right| j-u_{i} \mid j, / 27 /$

where $u_{i}=f\left(Z_{i}\right)=\delta_{0}+\sum_{i=1}^{M} \delta_{i} Z_{i}, Z_{i}$ and $\boldsymbol{\delta}$ are as earlier defined. The subscript $i=1,2, \ldots, M$ denotes firms and $j$ represents the different classes (groups). The vertical bar means that there is a different model for each class $j$ and the other variables are as previously defined. Now, $u_{i}$, which defines the inefficiency term, can be represented by non-negative unobservable random variables associated with the technical inefficiency of production, such that for a given technology and level of inputs, the observed output falls short of its potential (Battese-Coelli [1995]). 
The $Z$-vector parameter estimate for (in)efficiency level $(\hat{u})$ is expected to have a negative (positive) sign, which implies that the corresponding variable would reduce (increase) the level of (in)efficiency (Coelli et al. [2005]).

With regard to the latent class stochastic frontier model, although $u$ can take many distribution forms, we restricted our analysis to the widely used and supported latent class estimator by LIMDEP Version 11 Econometric Software: the normal half-normal and normal exponential-normal distributions (Greene [2016]). Further, these distributions were preferred for parsimony because they entail less computational complexity (Coelli et al. [2005]), unlike truncated and gamma, which, albeit flexible, sometimes may not be well identified and estimated (Ritter-Simar [1997]). In the LCSFA model, following Kumbhakar-Knox Lovell's [2000] formulation, the LF (latent class likelihood function) for each firm $i$ for group $j$ can be written as:

$$
L F_{i j}\left(\theta_{j}\right)=f\left(y_{i} \mid x_{i}, \boldsymbol{\beta}_{\mathbf{j}}, \sigma_{j}, \lambda_{j}\right)=\frac{\Phi\left(-\lambda_{j} \cdot \frac{\varepsilon_{i} \mid j}{\sigma_{j}}\right)}{\Phi(0)} \cdot \frac{1}{\sigma_{j}} \cdot \phi\left(\frac{\varepsilon_{i j}}{\sigma_{j}}\right),
$$

where $L F$ is the likelihood function for firm $i$ in group $j$, $\varepsilon_{i} \mid j=y_{i}-f\left(\beta_{j}^{\prime} x_{i}\right), \sigma_{j}=\sqrt{\sigma_{u j}^{2}+\sigma_{v j}^{2}}, \lambda=\frac{\sigma_{u j}^{2}}{\sigma_{v j}^{2}} . \Phi($.$) and \phi($.$) are standard nor-$ mal density and cumulative distribution functions, respectively. The LF for each firm can be obtained as a weighted average of its LF for each group $j$, using the prior probabilities $P_{i j}$ of class $j$ membership as weights:

$$
L F_{i}=\sum_{j=1}^{J} P_{i j} L F_{i j},
$$

where $0 \leq P_{i j} \leq 1$, and the sum of these probabilities for each firm must be $1: \sum_{j=1}^{J} P_{i j}=1$. To satisfy these two conditions, the class probabilities can be parameterized as a multinomial logit model expressed as:

$$
P_{i j}\left(\delta_{j}\right)=\frac{\exp \left(\delta_{j} q_{i}\right)}{\sum_{j=1}^{J} \exp \left(\delta_{j} q_{i}\right)},
$$

where $\delta_{j}$ is a vector of parameters to be estimated, $j=1, \ldots, J$, and $\delta_{j}=0 . q_{i}$ is the vector of 'separating variables' of firm-specific characteristics that sharpen the prior 
probabilities. The overall $\log$ LF is obtained as the sum of individual log LFs and can be written as:

$$
\log L F(\theta, \boldsymbol{\delta})=\sum_{i=1}^{N} \log L F_{i}(\theta, \boldsymbol{\delta})=\sum_{i=1}^{N} \log \left[\sum_{j=1}^{J} L F_{i j}\left(\theta_{j}\right) \cdot P_{i j}\left(\delta_{j}\right)\right]_{i} .
$$

The $\log$ LF can be maximized with respect to the parameter set $\theta_{j}=\left(\beta_{j}, \sigma_{j}, \lambda_{j}, \delta_{j}\right)$ using conventional methods (Greene [2002]). The estimated parameters can be used to compute the conditional posterior class probabilities. Following the steps outlined in Greene [2002], the posterior class probabilities can be obtained from:

$$
P_{i j}(j \mid i)=\frac{L F_{i j}\left(\theta_{j}\right) \cdot P_{i j}\left(\delta_{j}\right)}{\sum_{j=1}^{J} L F_{i j}\left(\theta_{j}\right) \cdot P_{i j}\left(\delta_{j}\right)} .
$$

This expression shows that the posterior class probabilities depend not only on the estimated $\delta$ parameters but also on the vector $\theta$, that is, the parameters from the production frontier. This means that an LCM classifies the sample into several classes even when sample-separating information is not available. In this case, the latent class structure uses the goodness of fit of each estimated frontier as additional information to identify classes of firms.

\subsection{Technical inefficiency and RTS measurement}

The ultimate goal of fitting frontier models is to estimate the technical inefficiency term in the stochastic model, $u_{i}$, from the observations. Again, it is not possible to estimate $u_{i}$ in LCM directly from any observed sample information. In the present case of a latent class stochastic frontier model, we estimate as many frontiers as there are number of classes. What remains an issue is how to measure the efficiency level of an individual firm when there is no unique technology against which inefficiency is to be computed. In a traditional stochastic frontier model, output-oriented TE can be calculated as a ratio of the observed output to the corresponding frontier output, given the available technology (Equation /15/). In the LCSFA model, the calculation of TE is tedious because each firm can be assigned to several frontiers, each one with an associated probability. Then, based on Orea-Kumbhakar [2004], TE can be 
measured with respect to the most likely frontier (the one with the highest posterior probability), or using a weighted average of the TE for all frontiers with the posterior probabilities as weights. This scheme of random weighting and random selection of the so-called reference technology can be avoided by using the following expression:

$$
T E_{i}=\sum_{j=1}^{J} P_{i j}(j \mid i) * T E_{i}(j),
$$

where $P_{i j}(j \mid i)$ are posterior class probabilities of being in the $j$-th class for a given firm $i$ defined in Equation $/ 24 /, 0<P_{i j}(j \mid i)<1$ and $\sum_{j=1}^{J} P_{i j}(j \mid i)=1$, while $T E_{i}(j)$ is its efficiency using the technology of class $j$ as the reference technology. Once estimates of TE are obtained, the indirect estimator of inefficiency can be obtained using $T I=1-\exp \left(-T E_{i}\right)$. This is the inefficiency parameter that enters into the inefficiency effects model as the dependent variable.

Since output and input variables were normalized by their means prior to estimation and are all expressed in natural logarithms, it is possible to calculate output elasticities by partially differentiating the LCSF model (Equations /17/ and /18/) by each of the inputs as follows:

$$
\frac{\partial Y_{i}}{\partial X_{i}}\left|j=E_{i}\right| j=\beta_{i} \mid j \text { and } R T S_{i}\left|j=\sum_{j=1}^{J} E_{i}\right| j,
$$

where RTS represents returns to scale. The elasticities are computed for each variable with respect to their individual frontiers, as indicated by the $J$ subscript, and these reflect the importance of each of the inputs in output production, while the sum of all input elasticities provides a measure of RTS for each firm $i$ in each class $j$.

For the log likelihood test, the null hypothesis relates to the adequacy test of the stochastic frontier model relative to the OLS model with normal errors. These tests involve the null hypothesis $\left(H_{0}: \sigma_{u}^{2}=0\right)$ against the alternative hypothesis $\left(H_{0}: \sigma_{u}^{2}>0\right)$. Additionally, it also tests the hypothesis that all coefficients and cross products for the translog model are equal to zero $\left(H_{0}: \beta^{\prime} s=0\right)$; this hypothesis was rejected. Thus, the stochastic frontier Cobb-Douglas and translog production function constitute an appropriate approximation for our livestock production analysis. 


\section{Conclusion}

This study discusses the two most widely used methods of production efficiency measurement: parametric SFA and non-parametric DEA. The non-parametric DEA form has some limitations in that its deterministic frontier attributes all deviations from the frontier to inefficiency and ignores any stochastic noise in the data; therefore, parametric SFA is preferred. The basis for this preference lies in its stochastic treatment of deviations from the frontier, which are decomposed into a non-negative inefficiency term and a random disturbance term that accounts for measurement errors and other random noise so that the measure is more consistent with the potential production under 'normal' working conditions. However, traditional SFA models assume homogeneous production technologies and the possible presence of heterogeneity needs to be incorporated when measuring TE. In such a situation, a one-stage latent class stochastic frontier model can be preferred over a two-stage where a sample is split using only observable characteristics. The study also highlights a possible remedy to the so-called 'wrong skewness' anomaly in stochastic frontiers; this is a direct consequence of the basic hypotheses, which appear to be overly restrictive. In fact, by relaxing the hypotheses of random error symmetry and independence of the components of the composite error, one can obtain a respecification of the stochastic frontier model that is sufficiently flexible by decomposing the third moment of the composite error into three components that include the asymmetry of the inefficiency term, the asymmetry of the random error, and the dependence structure of the error components. Last, a principal-components-based solution for multicollinearity in a stochastic frontier model can be adopted, instead of excluding insignificant variables from the model.

\section{References}

Aigner, D. J. - Lovell, K. - SchmidT, P. [1977]: Formulation and estimation of stochastic frontier production function models. Journal of Econometrics. Vol. 6. No. 1. pp. 21-37. https://doi.org/10.1016/0304-4076(77)90052-5

ALMANIDIS, P. - QIAN J. - SiCKLES, R. C. [2014]: Stochastic frontier models with bounded inefficiency. In: Sickles, R. C. - Horrace, W. C. (eds.): Festschrift in Honor of Peter Schmidt: Econometric Methods and Applications. Springer. New York. pp. 47-81.

AlmANidis, P. - Sickles, R. C. [2011]: The skewness issue in stochastic frontiers models: fact or fiction? In: Van Keilegom, I. - Wilson, P. W. (eds.): Exploring Research Frontiers in Contemporary Statistics and Econometrics. Springer. Berlin. pp. 201-227.

AlvareZ, A. - Arias, C. [2013]. Are Dairy Farms Becoming More Intensive? Impact on Farm Efficiency. Efficiency Series Papers. No. 2013/01. University of Oviedo, Department of Economics, Oviedo Efficiency Group. Oviedo. 
Alvarez, A. - Del Corral, J. - Solís, D. - Pérez, J. A. [2008]. Does intensification improve the economic efficiency of dairy farms? Journal of Dairy Science. Vol. 91. Issue 9. pp. 3699-3709. https://doi.org/10.3168/jds.2008-1123

Alvarez, A. - Del Corral, J. - TAUER, L. W. [2012]: Modeling unobserved heterogeneity in New York dairy farms: one-stage versus two-stage models. Agricultural and Resource Economics Review. Vol. 41. No. 3. pp. 275-285. https://doi.org/10.1017/S1068280500001258

AlvareZ, A. - DEL CORRAL, J. [2010]: Identifying different technologies using a latent class model: extensive versus intensive dairy farms. European Review of Agricultural Economics. Vol. 37. No. 2. pp. 231-250. https://doi.org/10.1093/erae/jbq015

ANDOR, M. - Hesse, F. [2014]: The StoNED age: the departure into a new era of efficiency analysis? A Monte Carlo comparison of StoNED and the 'oldies' (SFA and DEA). Journal of Productivity Analysis. Vol. 41. No. 1. pp. 85-109. https://doi.org/10.2139/ssrn.2200837

Assaf, A. G. - Josiassen, A. [2016]: Frontier analysis: a state-of-the-art review and meta-analysis. Journal of Travel Research. Vol. 55. No. 5. pp. 612-627. https://doi.org/10.1177/ 0047287515569776

Bahta, S. - Temoso, O. - Mekonnen, D. - Malope, P. - StaAl, S. [2018]: Technical Efficiency of Beef Production in Agricultural Districts of Botswana: A Latent Class Stochastic Frontier Model Approach. Paper presented at the $10^{\text {th }}$ International Conference of Agricultural Economists. 28 July - 2 August. Vancouver.

Balcombe, K. I. - RAhman, F. M. - Smith, L. [2007]: Examining the technical efficiency of rice producers in Bangladesh. Journal of International Development. Vol. 19. No. 1. pp. 1-16. https://doi.org/10.1002/jid.1284

BARÁTH, L. - FERTŐ, I. [2013]: Heterogenitás és technikai hatékonyság - a magyar specializált szántóföldi növénytermesztő üzemek esete. Közgazdasági Szemle. Vol. LX. May. pp. 650-669.

BARÁTH, L. - FERTŐ, I. [2015]: Heterogeneous technology, scale of land use and technical efficiency: the case of Hungarian crop farms. Land Use Policy. Vol. 42. January. pp. 141-150. https://doi.org/10.1016/j.landusepol.2014.07.015

BARros, C. P. - WANKe, P. [2014]: Insurance companies in Mozambique: a two-stage DEA and neural networks on efficiency and capacity slacks. Applied Economics. Vol. 46. No. 29. pp. 3591-3600. https://doi.org/10.1080/00036846.2014.934436

BAttese, G. E. - Coelli, T. J. [1988]: Prediction of firm-level technical efficiencies with a generalized frontier production function and panel data. Journal of Econometrics. Vol. 38. Issue 3. pp. 387-399. https://doi.org/10.1016/0304-4076(88)90053-X

BAtTeSE, G. E. - COELLI, T. J. [1992]: Frontier production functions, technical efficiency and panel data: with application to paddy farmers in India. Journal of Productivity Analysis. Vol. 3. Issues 1-2. pp. 153-169. https://doi.org/10.1007/BF00158774

Battese, G. E. - Coelli, T. J. [1995]: A model for technical inefficiency effects in a stochastic frontier production function for panel data. Empirical Economics. Vol. 20. No. 2. pp. 325-332. https://doi.org/10.1007/BF01205442

BATTESE, G. E. - CORRA, G. S. [1977]: Estimation of a production frontier model: with application to the pastoral zone of eastern Australia. Australian Journal of Agricultural Economics. Vol. 21. No. 3. pp. 169-179. https://doi.org/10.1111/j.1467-8489.1977.tb00204.x

Battese, G. E. - RAO, D. S. P. [2002]: Technology gap, efficiency and a stochastic metafrontier function. International Journal of Business and Economics. Vol. 1. No. 2. pp. 1-7. 
BAtTese, G. E. - RAO, P. - O'DONNEll, C. [2004]: A metafrontier production function for estimation of technical efficiencies and technology gaps for firms operating under different technologies. Journal of Productivity Analysis. Vol. 21. No. 1. pp. 91-103. https://doi.org/ 10.1023/B:PROD.0000012454.06094.29

Benr, A. [2015]: Production and Efficiency Analysis with $R$. Springer. New York. https://doi.org/10.1007/978-3-319-20502-1

Belotti, F. - Daidone, S. - Ilardi, G. - Atella, V. [2013]: Stochastic frontier analysis using Stata. The Stata Journal. Vol. 13. No. 4. pp. 719-758. https://doi.org/10.1177/ 1536867X1301300404

Berger, A. N. - Humphrey, D. B. [1992]: Measurement and efficiency issues in commercial banking. In: Griliches, Z. (ed.): Measurement Issues in the Service Sector. NBER Working Paper. No. 5519. National Bureau of Economic Research. Chicago. https://doi.org/10.3386/w5519

Bonanno, G. - De Giovanni, D. - Domma, F. [2017]: The 'wrong skewness' problem: a respecification of stochastic frontiers. Journal of Productivity Analysis. Vol. 47. No. 1. pp. 49-64. https://doi.org/10.1007/s11123-017-0492-8

BRUMmer, B. - LOY J. P. [2000]: The technical efficiency impact of farm credit programmes: a case study in Northern Germany. Journal of Agricultural Economics. Vol. 51. No. 3. pp. 405-418. https://doi.org/10.1111/j.1477-9552.2000.tb01239.x

Bruno, G. [1987]: 'Pareto, Vilfredo'. The New Palgrave: A Dictionary of Economics. Vol. 5. pp. 799-804.

CARREe, M. A. [2002]: Technological inefficiency and the skewness of the error component in stochastic frontier analysis. Economics Letters. Vol. 77. No. 1. pp. 101-107. https://doi.org/ 10.1016/S0165-1765(02)00119-2

CASTANO, E. - Gallon, S. [2017]: A solution for multicollinearity in stochastic frontier production function models. Lecturas de Economía. Vol. 86. pp. 9-23. https://doi.org/10.17533/ udea.le.n86a01

Chambers, R. G. [1988]: Applied Production Analysis: A Dual Approach. Cambridge University Press. Cambridge.

Charnes, A. - CoOper, W. W. - Rhodes, E. [1978]: Measuring efficiency of decision making units. European Journal of Operational Research. Vol. 2. Issue 6. pp. 429-444. https://doi.org/10.1016/0377-2217(78)90138-8

Coelli, T. - Henningsen, A. [2017]: Package 'Frontier'. The R Project for Statistical Computing. https://cran.r-project.org/web/packages/frontier/frontier.pdf

Coelli, T. - RaO, D. S. P. - O’Donnell, C. J. - Battese, G. E. [2005]: An Introduction to Efficiency and Productivity Analysis. $2^{\text {nd }}$ Edition. Springer. New York.

CoELLI, T. J. [1995]: Recent developments in frontier modelling and efficiency measurement. Australian Journal of Agricultural Economics. Vol. 39. No. 3. pp. 219-245. https://doi.org/10.1111/j.1467-8489.1995.tb00552.x

Coelli, T. J. [1996]: A Guide to Frontier Version 4.1: A Computer Program for Stochastic Frontier Production and Cost Function Estimation. CEPA Working Paper. No. 96/07. Centre for Efficiency and Productivity Analysis, University of New England. Armidale.

CORNwell, C. - SCHMidT, P. - SiCKLES, R. C. [1990] Production frontiers with cross-sectional and time-series variation in efficiency levels. Journal of Econometrics. Vol. 46. Issues 1-2. pp. 185-200. https://doi.org/10.1016/0304-4076(90)90054-W 
CULlmann, A. - FARSI, M. - FiliPPINI, M. [2012]: Unobserved heterogeneity and efficiency measurement in public transport. Journal of Transport Economics and Policy. Vol. 46. No. 1. pp. 51-66.

DAVIDON, W. C. [1991]: Variable metric method for minimization. SIAM (Social for Industrial and Applied Mathematics) Journal on Optimization. Vol. 1. No. 1. pp. 1-17.

Debreu, G. [1951]: The coefficient of resource utilization. Econometrica. Vol. 19. No. 3. pp. 273-292. https://doi.org/10.2307/1906814

Deprins, D. - Simar, L. - TulKens, H. [1984]: Measuring labor inefficiency in post offices. In: Marchand, M. - Pestieau, P. - Tulkens, H. (eds.): The Performance of Public Enterprises: Concepts and Measurements. North-Holland. Amsterdam. pp. 243-267.

FäRE, R. - LOVELL, C. K. [1978]: Measuring the technical efficiency of production. Journal of Economic Theory. Vol. 19. No. 1. pp. 150-162. https://doi.org/10.1016/0022-0531(78)90060-1

FARRELL, M. J. [1957]: The measurement of productive efficiency. Journal of the Royal Statistical Society. Series A. Vol. 120. No. 3. pp. 253-281. https://doi.org/10.2307/2343100

Feng, Q. - Horrace, W. C. - Wu, G. L. [2015]: Wrong Skewness and Finite Sample Correction in Parametric Stochastic Frontier Models. Center for Policy Research Working Papers. No. 154. Maxwell School.

FilipPini, M. - Hrovatin, N. - Zorić, J. [2008]: Cost efficiency of Slovenian water distribution utilities: an application of stochastic frontier methods. Journal of Productivity Analysis. Vol. 29. No. 2. pp. 169-182. https://doi.org/10.1007/s11123-007-0069-z

FletChER, R. - Powell, M. J. D. [1963]: A rapidly convergent descent method for minimization. The Computer Journal. Vol. 6. No. 2. pp. 163-168. https://doi.org/10.1093/comjnl/6.2.163

Galanopoulos, K. - Aggelopoulos, S. - Kamenidou, I. - Mattas, K. [2006]: Assessing the effects of managerial and production practices on the efficiency of commercial pig farming. Agricultural Systems. Vol. 88. Nos. 2-3. pp. 125-141. https://doi.org/10.1016/ j.agsy.2005.03.002

GREEN, A. - MAYES, D. [1991]: Technical inefficiency in manufacturing industries. The Economic Journal. Vol. 101. No. 4. pp. 523-538. https://doi.org/10.2307/2233557

GrEenE, W. H. [1990]: A gamma-distributed stochastic frontier model. Journal of Econometrics. Vol. 46. Nos. 1-2. pp. 141-163. https://doi.org/10.1016/0304-4076(90)90052-U

Greene, W. H. [2002]: Alternative Panel Data Estimators for Stochastic Frontier Models. Working Paper. New York University. New York.

GREENE, W. H. [2003]: Simulated likelihood estimation of the normal-gamma stochastic frontier function. Journal of Productivity Analysis. Vol. 19. Issues 2-3. pp. 179-190. https://doi.org/10.1023/A:1022853416499

GREENE, W. H. [2005]: Reconsidering heterogeneity in panel data estimators of the stochastic frontier model. Journal of Econometrics. Vol. 126. Issue 2. pp. 269-303. https://doi.org/10.1016/j.jeconom.2004.05.003

GreENE, W. H. [2012]: Econometric Analysis. $7^{\text {th }}$ Edition. Upper Saddle River. Prentice Hall.

GREENE, W. H. [2016]: LIMDEP, Version 11. Econometric Software, Incorporated. Plainview.

GROß, J. [2003]: Linear Regression. Lecture Notes in Statistics. Vol. 175. Springer. Berlin.

HAFner, C. M. - MANner, H. - Simar, L. [2018]: The "wrong skewness" problem in stochastic frontier models: a new approach. Econometric Reviews. Vol. 37. No. 4. pp. 380-400. https://doi.org/10.1080/07474938.2016.1140284 
HAJI, J. [2006]: Production efficiency of smallholder's vegetable-dominated farming systems in Eastern Ethiopia: a non-parametric approach. Journal of African Economies. Vol. 16. No. 1. pp. 1-27. https://doi.org/10.1093/jae/ej1044

Henderson, D. J. - SiMAR, L. [2005]. A Fully Nonparametric Stochastic Frontier Model for Panel Data. Discussion Paper. No. 0417. Institut de Statistique, Université Catholique de Louvain. Louvain.

HuANG, C. J. - LIU, J. T. [1994]: Estimation of a non-neutral stochastic frontier production function. Journal of Productivity Analysis. Vol. 5. Issue 2. pp. 171-180. https://doi.org/10.1007/ BF01073853

Jondrow, J. - Lovell, C. - Materov, I. - Schmidt, P. [1982]: On the estimation of technical efficiency in the stochastic production function model. Journal of Econometrics. Vol. 19. Issues 2-3. pp. 233-238. https://doi.org/10.1016/0304-4076(82)90004-5

Kellermann, M. [2014]: On the Measurement of Efficiency and Productivity under Firm Heterogeneity. Doctoral dissertation. Technische Universität München. München.

Khoo-FAZARI, K. - YAng, Z. - PARADI, J. C. [2013]: A distribution-free approach to stochastic efficiency measurement with inclusion of expert knowledge. Journal of Applied Mathematics. Article ID 102163. http://dx.doi.org/10.1155/2013/102163

KočIŠOVÁ, K. [2015]: Application of the DEA on the measurement of efficiency in the EU countries. Agricultural Economics. Vol. 61. No. 2. pp. 51-62. https://doi.org/10.17221/107/2014AGRICECON

KumbHAKAR, S. - GHOSH, S. - MCGUCKIN, J. [1991]: A generalized production frontier approach for estimating determinants of inefficiency in US dairy farms. Journal of Business and Economic Statistics. Vol. 9. No. 3. pp. 279-286. https://doi.org/10.2307/1391292

KumbhaKaR, S. C. - Efthymios, G. T. [2008]: Estimation of input-oriented technical efficiency using a non-homogeneous stochastic production frontier model. Agricultural Economics. Vol. 38. No. 1. pp. 99-108. https://doi.org/10.1111/j.1574-0862.2007.00285.x

Kumbhakar, S. C. - Park, B. U. - Simar, L. - Tsionas, E. G. [2007]: Nonparametric stochastic frontiers: a local maximum likelihood approach. Journal of Econometrics. Vol. 137. No. 1. pp. 1-27. https://doi.org/10.1016/j.jeconom.2006.03.006

KumbHAKAR, S. C. - TsionAS, E. G. - SiPILÄINEN, T. [2009]: Joint estimation of technology choice and technical efficiency: an application to organic and conventional dairy farming. Journal of Productivity Analysis. Vol. 31. No. 3. pp. 151-161. https://doi.org/10.1007/s11123-008-0081-y

KumBhaKaR, S. C. [1990]: Production frontiers, panel data, and time-varying technical inefficiency. Journal of Econometrics. Vol. 46. Issues 1-2. pp. 201-211. https://doi.org/10.1016/03044076(90)90055-X

Kumbhakar, S. C. - Knox Lovell, C. A. [2000]: Stochastic Frontier Analysis. Cambridge University Press. Cambridge, New York, Melbourne.

Kuosmanen, T. - Kortelainen, M. [2012]: Stochastic non-smooth envelopment of data: semiparametric frontier estimation subject to shape constraints. Journal of Productivity Analysis. Vol. 38. No. 1. pp. 11-28. https://doi.org/10.1007/s11123-010-0201-3

LEE, Y. H. - SchMiDT, P. [1993]: A production frontier model with flexible temporal variation in technical efficiency. In: Fried, H. O. - Knox Lovell, C. A. - Schmidt, S. S. (eds.): The Measurement of Productive Efficiency: Techniques and Applications. Oxford University Press. New York. pp. 237-255. 
MamardashVili, P. - BoKusheVA, R. [2014]: Heterogeneous farm output and technical efficiency estimates. German Journal of Agricultural Economics. Vol. 63. No. 1. pp. 16-30.

MANYEKI, J. K. - KotosZ, B. [2019]: Efficiency estimation and its role in policy recommendations: an application to the Kenyan livestock sector. Regional Science Policy \& Practice. Vol. 11. Issue 2. pp. 367-381. https://doi.org/10.1111/rsp3.12197

Martinez, C. M. - Breen, J. - Thorne, F. - Wallace, M. - Hennessy, T. [2016]: Technical Efficiency and Technology Heterogeneity of Beef Farms: A Latent Class Stochastic Frontier Approach. Paper presented at the $90^{\text {th }}$ Annual Conference. 4-6 April. Warwick University. Coventry. https://ideas.repec.org/s/ags/aesc16.html.

Martins-Filho, C. - YAO, F. [2015]: Semiparametric stochastic frontier estimation via profile likelihood. Econometric Reviews. Vol. 34. No. 4. pp. 413-451. https://doi.org/10.1080/ 07474938.2013.806729

MAudos, J. - PAStOR, J. - PÉREZ, F. [2002]: Competition and efficiency in the Spanish banking sector: the importance of specialization. Applied Financial Economics. Vol. 12. Issue 7. pp. 505-516. https://doi.org/10.1080/09603100010007977

MEEUSEN, W. - VAN DEN BROECK, J. [1977]: Efficiency estimation from Cobb-Douglas production functions with composed error. International Economic Review. Vol. 18. No. 2. pp. 435-444. https://doi.org/10.2307/2525757

Melo-Becerra, L. A. - Orozco-Gallo, A. J. [2017]: Technical efficiency for Colombian small crop and livestock farmers: a stochastic metafrontier approach for different production systems. Journal of Productivity Analysis. Vol. 47. No. 1. pp. 1-16. https://doi.org/10.1007/s11123-0160487-x

Moreira, V. H. - Bravo-UretA, B. E. [2010]: Technical efficiency and metatechnology ratios for dairy farms in three Southern cone countries: a stochastic meta-frontier model. Journal of Productivity Analysis. Vol. 33. No. 1. pp. 33-45. https://doi.org/10.1007/s11123-009-0144-8

Newman, C. - MatTHEws, A. [2006]. The productivity performance of Irish dairy farms 19842000: a multiple output distance function approach. Journal of Productivity Analysis. Vol. 26. No. 2. pp. 191-205. https://doi.org/10.1007/s11123-006-0013-7

OREA, L. - KUMBHAKAR, S. [2004]: Efficiency measurement using a latent class stochastic frontier model. Empirical Economics. Vol. 29. No. 1. pp. 169-183. https://doi.org/10.1007/s00181003-0184-2

Otieno, D. J. - HubBard, L. - Ruto, E. [2014]: Assessment of technical efficiency and its determinants in beef cattle production in Kenya. Journal of Development and Agricultural Economic. Vol. 6. No. 6. pp. 267-278. https://doi.org/10.5897/JDAE2013.0525

PARK, B. U. - SimAR, L. - ZelENYUK, V. [2008]: Local likelihood estimation of truncated regression and its partial derivatives: theory and application. Journal of Econometrics. Vol. 146. No. 1. pp. 185-198. https://doi.org/10.1016/j.jeconom.2008.08.007

PitT, M. M. - LEE L. F. [1981]: The measurement and sources of technical inefficiency in the Indonesian weaving industry. Journal of Development Economics. Vol. 9. Issue 1. pp. 43-64. https://doi.org/10.1016/0304-3878(81)90004-3

Poghosyan, T. - Kumbhakar, S. C. [2010]: Heterogeneity of technological regimes and banking efficiency in former socialist economies. Journal of Productivity Analysis. Vol. 33. No. 1. pp. 19-31. https://doi.org/10.2139/ssrn.1323042 
QIAN, J. - SickLeS, R. C. [2009]: Stochastic Frontiers with Bounded Inefficiency. Rice University Working Paper. http://jhqian.org/AQS2013.pdf

RITTER, C. - SIMAR, L. [1997]: Pitfalls of normal-gamma stochastic frontiers and panel data. Journal of Productivity Analysis. Vol. 8. No. 2. pp. 167-182. https://doi.org/10.1023/ A: 1007751524050

Sauer, J. - Davidova, S. - Gorton, M. [2012]: Heterogeneous Technologies as an Answer to Market and Price Risk: The Case of Kosovo. Paper presented at the EAAE (European Association of Agricultural Economists) $123^{\text {rd }}$ Seminar. 23-24 February. Dublin.

SAUER, J. - MORRISON PAUL, C. J. [2013]: The empirical identification of heterogeneous technologies and technical change. Applied Economics. Vol. 45. No. 11. pp. 1461-1479. https://doi.org/10. 1080/00036846.2011.617704

SCHMIDT, P. [2011]: One-step and two-step estimation in SFA models. Journal of Productivity Analysis. Vol. 36. No. 2. pp. 201-203. https://doi.org/10.1007/s11123-011-0228-0

SIMAR, L. - WILSON, P. [2010]: Inferences from cross-sectional, stochastic frontier models. Economic Review. Vol. 29. No. 1. pp. 62-98. https://doi.org/10.1080/07474930903324523

Simon, H. A. [1957]: Models of Man, Social and Rational: Mathematical Essays on Rational Human Behavior in a Social Setting. John Wiley and Sons. New York.

StATACoRP, L. L. P. [2011]: Stata/SE Version 12.1 (Computer Software). Stata Corp, LLP. College Station.

STEVENSON, R. [1980]: Likelihood functions for generalized stochastic frontier estimation. Journal of Econometrics. Vol. 13. No. 1. pp. 57-66. https://doi.org/10.1016/0304-4076(80)90042-1

Straub, A. - Straub, M. A. [2016]: Package 'sfa'. The R Project for Statistical Computing. $\mathrm{ftp} / / / \mathrm{ftp}$. uvigo.es/CRAN/web/packages/sfa/sfa.pdf

Tsionas, E. G. [2007]: Efficiency measurement with the Weibull stochastic frontier. Oxford Bulletin of Economic Statistics. Vol. 69. No. 5. pp. 693-706. https://doi.org/10.1111/j.14680084.2007.00475.x

VAN HeERden, C. - Rossouw, R. [2014]: Resource utilisation efficiency: a South African provincial evaluation. South African Journal of Economics. Vol. 82. No. 4. pp. 475-492. https://doi.org/10.1111/saje.12037

VIDOLI, F. - FERRARA, G. [2015]: Analyzing Italian citrus sector by semi-nonparametric frontier efficiency models. Empirical Economics. Vol. 49. No. 2. pp. 641-658. https://doi.org/10.1007/s00181-014-0879-6

WaLdman, D. M. [1982]: A stationary point for the stochastic frontier likelihood. Journal of Econometrics. Vol. 18. Issue 2. pp. 275-279. https://doi.org/10.1016/0304-4076(82)90041-0

WIDMER, P. K. [2015]: Does prospective payment increase hospital (in) efficiency? Evidence from the Swiss hospital sector. The European Journal of Health Economics. Vol. 16. No. 4. pp. 407-419. https://doi.org/10.1007/s10198-014-0581-9 